\title{
Sensitivity of Brazilian Isolates of Phytophthora infestans to Commonly Used Fungicides in Tomato and Potato Crops
}

\author{
Ailton Reis, Fabiana H. S. Ribeiro, Luiz A. Maffia, and Eduardo S. G. Mizubuti, Departamento de Fitopatologia, \\ Universidade Federal de Viçosa, 36570-000, Viçosa-MG, Brazil
}

\begin{abstract}
Reis, A., Ribeiro, F. H. S., Maffia, L. A., and Mizubuti, E. S. G. 2005. Sensitivity of Brazilian isolates of Phytophthora infestans to commonly used fungicides in tomato and potato crops. Plant Dis. 89:1279-1284.

Isolates of the US-1 and BR-1 clonal lineages of Phytophthora infestans, collected from tomato and potato fields of two main producing regions of Brazil (south and southeast), were tested for sensitivity to the systemic fungicide metalaxyl, plus the three protectant fungicides mancozeb, chlorothalonil, and cymoxanil. For metalaxyl, one agar test and two leaf-disc tests were carried out. For all tests, metalaxyl insensitive (I), intermediately insensitive (II), and sensitive (S) isolates were detected. There was no association among metalaxyl sensitivity and region, lineage, or host. In the agar test, $35.0 \%$ of 210 isolates were classified as I, $36.0 \%$ as II, and $29.0 \%$ as S. US-1 isolates were classified as $36.1 \%$ I, $30.6 \%$ II, and $33.3 \% \mathrm{~S}$. BR-1 isolates were $33.3 \% \mathrm{I}$, $23.8 \%$ II, and $42.9 \% \mathrm{~S}$. In leaf-disc test 1 (240 isolates tested), $24.3 \%$ were classified as I, $35.0 \%$ as II, and $40.7 \%$ as S. Isolates of US-1 were $21.0 \%$ I, 39.8\% II, and $39.2 \%$ S, whereas BR-1 isolates were $36.0 \%$ I, $20.0 \%$ II, and $44.0 \%$ S. In leaf-disc test 2 (96 isolates tested), which was based on an effective dose for $50 \%$ sporulation inhibition $\left(\mathrm{ED}_{50}\right)$, most isolates were either I $(44.8 \%)$ or II $(51.0 \%)$, and only three $(4.2 \%)$ were S. The US-1 isolates were $46.0 \%$ I, $51.0 \%$ II, and $3.0 \%$ S. Isolates of the BR-1 lineage were $45.0 \%$ I, 52.0\% II, and $3.0 \% \mathrm{~S}$. For mancozeb, the $\mathrm{ED}_{50}$ for 53 of 59 isolates was below $1.0 \mu \mathrm{g} / \mathrm{ml}$. No isolate grew on medium amended with more than $100 \mu \mathrm{g}$ of chlorothalonil $/ \mathrm{ml}$ and the $\mathrm{ED}_{50}$ for 38 of 50 isolates was below $1.0 \mu \mathrm{g} / \mathrm{ml}$. For cymoxanil, the $\mathrm{ED}_{50}$ for all 47 isolates tested was below $1 \mu \mathrm{g} / \mathrm{ml}$. There is no evidence of resistance of $P$. infestans to protectant fungicides commonly used in Brazil.
\end{abstract}

Additional keywords: fungicide resistance, late blight

Tomato (Solanum lycopersicum L.) and potato (Solanum tuberosum L.) are the most important vegetable crops in Brazil. During 2002, production of tomato and potato in Brazil totaled 3.6 and 3.1 million tons, respectively (20). The major producing areas are the south and southeast regions (Table 1), in which $57.2 \%$ of the tomato and $92.3 \%$ of the potato are produced (20). Late blight, caused by Phytophthora infestans (Mont.) de Bary, occurs in both regions and is the most serious foliar disease of these crops. The environmental conditions in these regions also are highly favorable to late blight development (18), leading to severe crop losses if no control measures are adopted.

Corresponding author: E. S. G. Mizubuti E-mail: mizubuti@ufv.br

Current address of A. Reis: Embrapa Hortaliças, C. Postal 218, 70359-970, Brasília-DF, Brazil.

This work was conducted as research for a Ph.D. thesis of A. Reis. Financial support was provided by Fundação de Amparo à Pesquisa de Minas Gerais (FAPEMIG).

Accepted for publication 22 June 2005.

DOI: 10.1094/PD-89-1279

(C) 2005 The American Phytopathological Society
Due to favorable environmental conditions and high susceptibility to late blight, up to 20 and 15 fungicide sprays commonly are used in tomato and potato crops, respectively (30). Furthermore, host availability is high and, in many regions, three potato or tomato crops per year commonly are cultivated. Potato and processing tomato crops usually are sprinkler irrigated, whereas fresh-market tomato crops are furrow or drip irrigated. In both crops, the most commonly applied fungicides are copper oxychloride, mancozeb, chlorothalonil, cymoxanil (protectant), dimethomorph, propamocarb, and metalaxyl (systemic). Recently, tomato and potato growers have observed reduced efficacy of chemical control. This lack of efficacy could be related to environmental factors or fungicide insensitivity of $P$. infestans populations.

Selection of fungicide-insensitive individuals in populations of plant-pathogenic fungi is a common event and is reported more frequently for systemic fungicides $(7,8,14,24,25,29,42,43)$. Specifically for $P$. infestans, there is no evidence of field resistance to cymoxanil, copper oxychloride, mancozeb, or chlorothalonil (45), but there are several reports of resistance to metalaxyl $(5,14,26)$. This is a problem for growers because of fungicide waste ap- plied with inefficient disease control, as well as for chemical industries that have to either replace their products or restrict their usage. Thus, monitoring pathogen insensitivity, especially to systemic fungicides, is an important component of disease management $(14,46)$.

Phenylamide compounds were released at the end of the 1970s and, initially, they were very effective systemic fungicides with both protectant and curative effects against Oomycetes (14). Metalaxyl was one of the most effective phenylamides and has been applied intensively to control downy mildews in many crops and late blight in tomato and potato $(3,14)$. Due to its specific mode of action (13) and continuous usage, high selection pressure can be exerted and insensitive subpopulations may predominate in the field (46). In the early 1980 s, metalaxyl-insensitive isolates of $P$. infestans were reported in Europe $(4,9)$. Nevertheless, insensitive isolates were confined to specific areas with no reports of widespread distribution. In addition to evolution of metalaxyl resistance in established populations of $P$. infestans, migrations of new genotypes of $P$. infestans from Central Mexico contributed to the widespread distribution of metalaxylinsensitive isolates of $P$. infestans in North America (12). Some of the newly established genotypes reproduced mostly asexually, maintaining clonal populations. Nowadays, $P$. infestans populations in many countries outside Mexico are made up by one or a few clonal lineages and many of these new genotypes are metalaxyl insensitive (12).

Currently, in Brazil, two clonal lineages of $P$. infestans are reported: US-1 and BR1 (33). Each lineage is highly host specific: the US-1 isolates commonly are associated with tomato, whereas BR-1 isolates are found on potato (44). In other countries, such as the United States, US-1 isolates are metalaxyl sensitive whereas isolates of the lineages that were introduced as a result of recent migration events, such as US-7 and US-8, are metalaxyl insensitive (16). Interestingly, in the Toluca Valley, Mexico, where sexual reproduction of $P$. infestans occurs, resistance to metalaxyl reverted to baseline levels over a period of approximately 10 years $(17,27)$. Surveys and genetic studies of metalaxyl resistance of $P$. infestans isolates have been more intensively conducted in Europe and North America (10,14,21,26,37). Characteriza- 
tion of $P$. infestans isolates to metalaxyl sensitivity was conducted in South American countries (11) and recent data has become available for countries such as Chile (35), Peru (32), Uruguay (6), and Venezuela (36). However, no thorough study has been conducted to assess metalaxyl sensitivity of Brazilian isolates of $P$. infestans.

In Brazil, the only report on metalaxyl sensitivity was published as a meeting abstract with no details on general procedures related to methods of testing fungicide sensitivity and data analysis (2). A more detailed analysis using methods recommended by the Fungicide Resistance Action Committee (FRAC), namely agar and leaf-disc tests, needs to be carried out to address the metalaxyl sensitivity issue. Also, to date, we are not aware of any report of insensitivity of $P$. infestans to the most commonly used protectant fungicides in tomato and potato crops in Brazil. There are studies on pathogen sensitivity to mancozeb, chlorothalonil, and cymoxanil $(22,45)$ conducted under temperate conditions but few in tropical or subtropical areas.

In this research, we assessed the sensitivity of Brazilian isolates of $P$. infestans to metalaxyl, mancozeb, chlorothalonil, and cymoxanil. We also tested the hypothesis that Brazilian isolates of both clonal lineages of $P$. infestans, US-1 and BR-1, do not differ regarding metalaxyl sensitivity.

\section{MATERIALS AND METHODS}

$P$. infestans isolates. Tomato and potato fields located in seven states in the south and southeast regions of Brazil were sampled during 1998 to 2000 . A total of $258 P$. infestans isolates ( 87 from potato and 171 from tomato plants) was obtained from 122 fields (43 of potato and 79 of tomato) from both regions (Table 1). From each sampled field, we assessed one to five isolates for fungicide sensitivity. All isolates were characterized for mating type as described by Spielman et al. (41). Previous work conducted on the same isolates used in this study showed that all A1 mating type isolates were of the US-1 clonal lineage and all A2 isolates were BR-1 (33).
Sensitivity of $P$. infestans isolates to metalaxyl. Metalaxyl sensitivity was assessed with three tests: agar test, leaf-disc test 1 , and leaf-disc test 2 . Because of loss of viability, the number of isolates was not the same in all tests.

Agar test. The sensitivity of 210 isolates was assessed based on radial growth on metalaxyl-amended rye culture medium (rye-B), as described elsewhere $(27,40)$. An 8-mm-diameter mycelial plug from a 7-day-old colony was placed in the center of a petri plate containing rye-B amended with metalaxyl suspension, prepared from Ridomil 2E, to a final concentration of 0 , 5 , or $100 \mu \mathrm{g} / \mathrm{ml}$. For each isolate and metalaxyl concentration, two plates (replicates) were used. The plates were kept at $18^{\circ} \mathrm{C}$ in the dark. After 14 days, the colony diameter of all isolates was measured in two perpendicular directions previously marked at the bottom of the plate. Final radial growth was corrected by subtracting $8 \mathrm{~mm}$ of the mycelial plug from the measured colony diameter. Mean colony diameters in culture medium amended with metalaxyl at 5 or $100 \mu \mathrm{g} / \mathrm{ml}$ were divided by the mean colony diameter on the control plates and multiplied by 100 to determine relative growth. Isolates were rated as sensitive when relative growth was $<40 \%$ for metalaxyl at both 5 and 100 $\mu \mathrm{g} / \mathrm{ml}$, intermediately sensitive when relative growth was $>40 \%$ at $5 \mu \mathrm{g} / \mathrm{ml}$ and $<40 \%$ in $100 \mu \mathrm{g} / \mathrm{ml}$, or insensitive when relative growth was $>40 \%$ in both 5 and $100 \mu \mathrm{g} / \mathrm{ml}$ (27). The test was conducted twice and the mean of both trials was used in the analyses.

Leaf-disc test 1. Metalaxyl sensitivity of 240 isolates was assessed based on sporangial production of each isolate on leaf discs of its original host, tomato or potato $(27,40)$. Isolates were cultivated on detached leaflets of susceptible potato cv. Bintje or tomato cv. Kada. After sporulation, a $2 \times 10^{4}$ sporangia/ml suspension was prepared. Tomato or potato leaf discs (15 $\mathrm{mm}$ in diameter) were floated, abaxial side up, on a petri plate containing a solution of metalaxyl at 0,5 , or $100 \mu \mathrm{g} / \mathrm{ml}$. There were five leaf discs per plate and two plates (replicates) per treatment. A 20- $\mu \mathrm{l}$ drop of inoculum suspension $\left(2 \times 10^{4}\right.$ sporangia/ml) was deposited on each leaf disc and the discs were incubated under a 14-h photoperiod at 18 to $20^{\circ} \mathrm{C}$. After 6 to 7 days, the percentage of each leaf disc with symptoms or sporangia was rated under a dissecting microscope according to a six-grade scale in which $0=$ no apparent symptoms, $1=$ necrosis, $2=5 \%, 3=6$ to $20 \%, 4=21$ to $50 \%$, and $5=>50 \%$ of the disc surface was covered with pathogen sporulation (39). To determine isolate reaction to metalaxyl, sporulation at 5 and 100 $\mu \mathrm{g} / \mathrm{ml}$ was expressed as percentage of sporulation on control discs. The criteria previously described in the agar test were used to determine fungicide sensitivity. The test was conducted twice and the mean of both trials was used in the analyses.

Leaf-disc test 2. Metalaxyl sensitivity of 96 isolates was assessed according to methodology described by Sozzi et al. (39). Leaf discs (15 $\mathrm{mm}$ in diameter) of potato cv. Bintje or tomato cv. Kada were floated, abaxial side up, in a petri plate with a solution of metalaxyl (Ridomil 2E) at $0,0.01,0.1,1,10$, or $100 \mu \mathrm{g} / \mathrm{ml}$. Each leaf disc was inoculated with $20 \mu \mathrm{l}$ of a suspension of $2 \times 10^{4}$ sporangia/ml and incubated at 18 to $20^{\circ} \mathrm{C}$ with a 14-h photoperiod. After 6 to 7 days, the percentage of each leaf disc covered by fungal sporulation was estimated under a dissecting microscope. Sporulation was rated as described in leaf-disc test 1.

The test was conducted twice and the mean of both trials was used in the analyses. To determine isolate reaction to metalaxyl, the data were transformed to the Townsend-Heuberger index and adjusted by using the Abbot formula $(19,39)$. The Townsend-Heuberger index converts rating grade into percentage of leaf disc area with sporulation. The Abbot formula takes into account the amount of sporulation in the controls, which is not always equal to $100 \%$, for proper calculation of the amount of sporulation reduction in each treatment (19). The effective dose for $50 \%$ sporulation inhibition $\left(\mathrm{ED}_{50}\right)$ was estimated for each replicate. A linear regression model was fitted on sporulation

Table 1. Numbers of tomato and potato fields sampled between 1998 and 2000 in different states and regions of Brazil and of isolates of Phytophthora infestans obtained and tested for fungicide sensitivity ${ }^{\mathrm{a}}$

\begin{tabular}{|c|c|c|c|c|c|c|}
\hline \multirow[b]{2}{*}{ Region, state } & \multicolumn{3}{|c|}{ Number of sampled fields } & \multicolumn{3}{|c|}{ Number of isolates } \\
\hline & Tomato & Potato & Total & Tomato & Potato & Total \\
\hline \multicolumn{7}{|l|}{ South } \\
\hline Rio Grande do Sul & 1 & 6 & 7 & 1 & 10 & 11 \\
\hline Santa Catarina & 4 & 6 & 10 & 8 & 12 & 20 \\
\hline Paraná & 7 & 8 & 15 & 16 & 15 & 31 \\
\hline \multicolumn{7}{|l|}{ Southeast } \\
\hline São Paulo & 4 & 3 & 7 & 10 & 8 & 18 \\
\hline Rio de Janeiro & 13 & 0 & 13 & 26 & 0 & 26 \\
\hline Minas Gerais & 40 & 18 & 58 & 82 & 39 & 121 \\
\hline Espírito Santo & 10 & 2 & 12 & 28 & 3 & 31 \\
\hline Total & 79 & 43 & 122 & 171 & 87 & 258 \\
\hline
\end{tabular}

a All isolates from tomato and the majority (85 of 87) of the isolates from potato were of US-1 and of BR-1 clonal lineages, respectively. 
inhibition as a function of fungicide concentration, and the $\mathrm{ED}_{50}$ was estimated. According to Sozzi et al. (39), two criteria should be used to distinguish isolate reaction to metalaxyl. In criterion 1 , an isolate was rated as sensitive, intermediately insensitive, or insensitive if $\mathrm{ED}_{50}$ was $>0.001$ and $<0.01 \mu \mathrm{g} / \mathrm{ml},>0.01$ and $<10 \mu \mathrm{g} / \mathrm{ml}$, or $\geq 10 \mu \mathrm{g} / \mathrm{ml}$, respectively. In criterion 2 , an isolate was rated as sensitive or insensitive if $\mathrm{ED}_{50}$ was $<10 \mu \mathrm{g} / \mathrm{ml}$ or $\geq 10 \mu \mathrm{g} / \mathrm{ml}$, respectively.

Sensitivity of $P$. infestans isolates to mancozeb, chlorothalonil, and cymoxanil. Sensitivity to mancozeb, chlorothalonil, and cymoxanil was determined for 59 , 50 , and 47 isolates, respectively. The sensitivity to the fungicides was determined based on radial colony growth on rye flour agar (RFA) medium (34), in which each fungicide was added as described elsewhere (45).

Mycelium plugs ( $9 \mathrm{~mm}$ in diameter) of actively growing 7 - to 10 -day-old $P$. infestans colonies were cut with a cork borer and transferred to petri plates containing RFA amended with fungicides. Aliquots from a previously prepared stock suspension of mancozeb (Dithane 800PM) or chlorothalonil (Bravonil 750PM) in sterile distilled water were transferred to molten RFA medium. A working suspension of cymoxanil (technical grade) was prepared with dimethyl sulfoxide (DMSO). Final concentrations of each fungicide were 0.0 (control), 0.5, 1.0, 5.0, 10.0, 25.0, and $100.0 \mu \mathrm{g} / \mathrm{ml}$. Each isolate was grown in three petri plates (replicates) of each concentration-fungicide combination at $18^{\circ} \mathrm{C}$ in the dark. After 15 days, mycelial growth inhibition was expressed relative to the control, and $\mathrm{ED}_{50}$ for inhibition of mycelial growth was estimated for each replicate with regression analysis of mycelium growth by fungicide concentration.

All experiments were laid out in a completely randomized design and conducted twice, and the mean of both trials was used in the analyses. Independence analyses were carried out using $\chi^{2}$ tests (38). Varia- tion in the frequencies of the three classes of sensitivity (insensitive, intermediately insensitive, and sensitive) was analyzed by region (south and southeast) or clonal lineages (US-1 and BR-1).

\section{RESULTS}

Metalaxyl agar test. Of 210 isolates $35.2,28.6$, and $36.2 \%$ were scored as insensitive, intermediately insensitive, and sensitive to metalaxyl, respectively. The insensitive and intermediately insensitive isolates totaled $63.8 \%$.

There was no association between clonal lineage and metalaxyl sensitivity $\left(\chi^{2}\right.$ $=2.28, P=0.319)$. Metalaxyl insensitive, intermediately insensitive, and sensitive isolates were detected in both the US-1 (137 isolates) and BR-1 lineages (73 isolates) (Fig. 1A).

For the sample of 44 isolates from the south region, sensitive isolates occurred in higher frequency than intermediately insensitive or insensitive isolates (Fig. 1B). Of the 166 isolates from the southeast
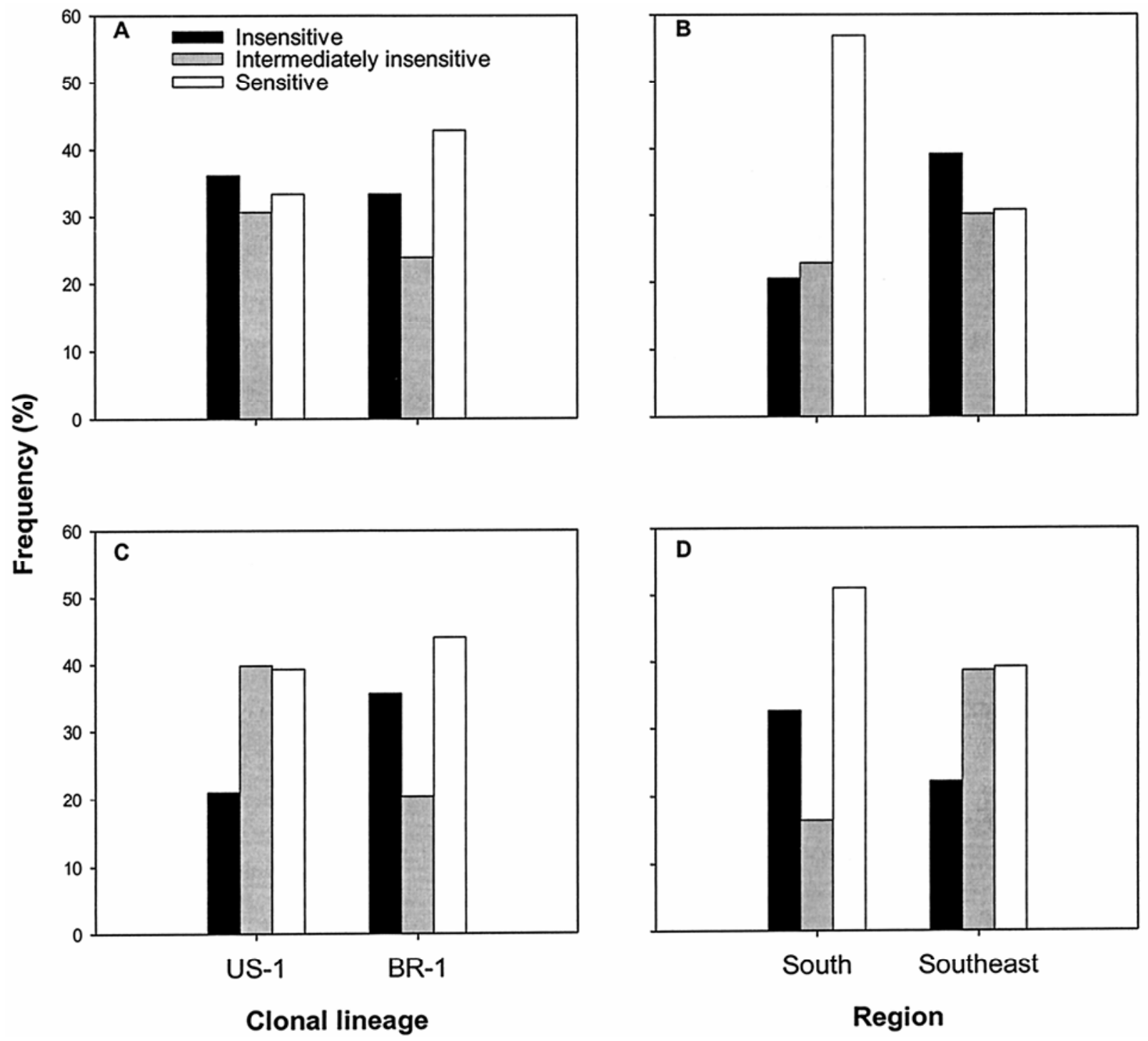

Fig. 1. Frequency of Phytophthora infestans isolates insensitive, intermediately insensitive, and sensitive to metalaxyl, evaluated by agar test (210 isolates) (A and B) and by leaf-disc test 1 (240 isolates) (C and D). Distribution of isolates according to clonal lineages (A and C) or sampling region (B and D). 
region, 39.2, 30.1, and $30.7 \%$ were insensitive, intermediately insensitive, and sensitive, respectively. The sum of insensitive and intermediately insensitive resulted in a higher frequency $(69.3 \%)$ than that of sensitive isolates (30.7\%) (Fig. 1B). Pooling all isolates, the frequency of insensitive and intermediately insensitive isolates in the southeast (69\%) was higher than in the south region $(43 \%)$.

Overall, the frequency of isolates in each sensitivity class varied among region $\left(\chi^{2}=10.66, P=0.005\right)$. Higher frequencies of insensitive and intermediately insensitive isolates were detected in the southeast than in the south.

Metalaxyl leaf-disc test 1. Among 240 isolates, 24,35 , and $41 \%$ were insensitive, intermediately insensitive, and sensitive to metalaxyl, respectively. Insensitive and intermediately insensitive isolates totaled $59 \%$ of the isolates.

Insensitive, intermediately insensitive, and sensitive isolates were detected within
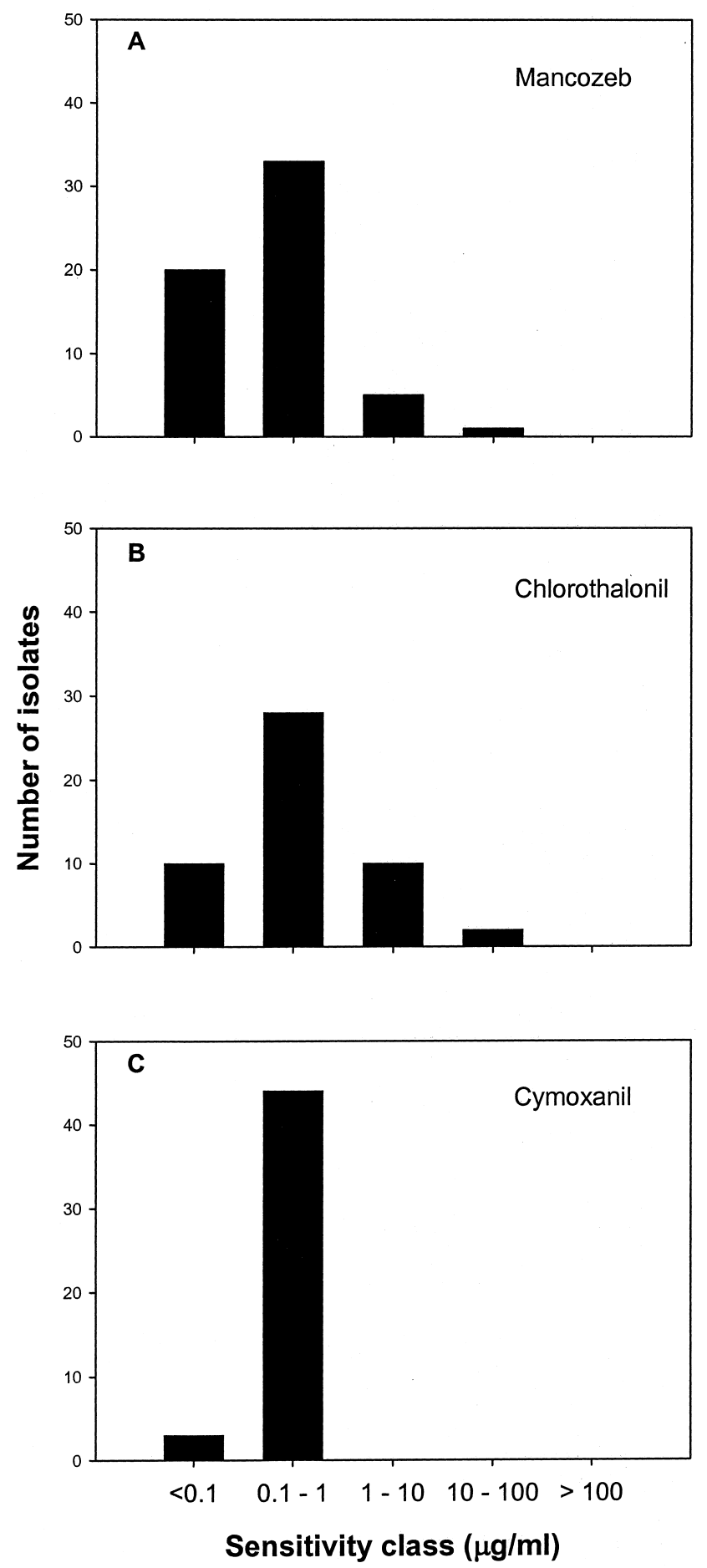

Fig. 2. Number of isolates of Phytophthora infestans in different classes of $\mathrm{ED}_{50}$ values estimated for the fungicides: A, mancozeb (59 isolates); B, chlorothalonil (50 isolates); and C, cymoxanil (47 isolates).

each lineage (Fig. 1C). However, the frequency of insensitive, intermediately insensitive, and sensitive isolates was not evenly distributed between the two lineages $\left(\chi^{2}=68.05, P<0.001\right)$. Among the 181 US-1 isolates, intermediately insensitive and sensitive prevailed over insensitive isolates (Fig. 1C). Among the 59 BR-1 isolates, intermediately insensitive isolates occurred less frequently than the other two classes (Fig. 1C).

In the sample of 49 isolates from the south, the frequency of sensitive isolates $(51 \%)$ was higher than the sum of the insensitive and intermediately insensitive isolates (49\%) (Fig. 1D). Among the 191 isolates from the southeast, intermediately insensitive and sensitive isolates were more frequent than insensitive isolates (Fig. 1D). There was a significantly higher frequency of insensitive and sensitive isolates in the south than in the southeast, whereas the frequency of intermediately insensitive isolates was higher in the southeast $\left(\chi^{2}=8.86, P=0.012\right)$. The sum of the frequencies of insensitive and intermediately insensitive isolates in the south and southeast were 49 and $61 \%$, respectively.

In the south region, 23 US-1 and 26 BR1 isolates were analyzed and the majority of insensitive isolates $(52.2 \%)$ were of the US-1 lineage. The frequencies of intermediately insensitive and sensitive isolates were 17.4 and $30.4 \%$, respectively. Among the BR-1 isolates, 15.4, 15.4, and $69.2 \%$ were insensitive, intermediately insensitive, and sensitive to metalaxyl, respectively. All tomato isolates were US-1 and all potato isolates were of the BR-1 lineage. Therefore, when grouped according to the host of origin (tomato or potato), the frequencies of insensitive, intermediately insensitive, and sensitive isolates were the same as those estimated when grouping isolates according to lineage.

In the southeast, 191 isolates (158 US-1 and 33 BR-1) were analyzed. Among the US-1 isolates, 17.4, 41.6, and $41 \%$ were insensitive, intermediately insensitive, and sensitive to metalaxyl, respectively. Among the BR-1 isolates, 45.5, 24.2, and $30.3 \%$ were insensitive, intermediately insensitive, and sensitive to metalaxyl, respectively. The frequency of tomato isolates (all US-1) insensitive to metalaxyl $(21 \%)$ was lower than that of intermediately insensitive $(39.8 \%)$ and sensitive isolates $(39.2 \%)$. Among the potato isolates (the majority BR-1), the frequency of insensitive isolates was higher $(35.6 \%)$ than that of intermediately insensitive $(20.3 \%)$ and sensitive isolates (44.1\%).

Metalaxyl leaf-disc test 2. Most of the 96 isolates were either insensitive $(44.8 \%)$ or intermediately insensitive $(51.0 \%)$, whereas only three isolates $(4.2 \%)$ were sensitive to metalaxyl. Using the second criterion of grouping isolates, $45 \%$ were considered insensitive and 55\% sensitive to metalaxyl. 
Grouping isolates according to clonal lineages generated similar results as when the population of isolates was considered as a whole. Among the 63 isolates of US-1, 46,51 , and $3 \%$ were insensitive, intermediately insensitive, and sensitive to metalaxyl, respectively. Among 33 BR-1 isolates, the frequencies of insensitive, intermediately insensitive, and sensitive were 45,52 , and $3 \%$, respectively.

Among the 20 isolates from the south, 28.6, 66.7, and $4.7 \%$ were insensitive, intermediately insensitive, and sensitive to metalaxyl, respectively. Among the 76 isolates from the southeast, the frequencies of insensitive, intermediately insensitive, and sensitive were $48,49.3$, and $2.7 \%$, respectively.

Tests using $\mathrm{ED}_{50}$ (leaf-disc test 2) resulted in a high number of insensitive isolates. According to criterion 2, almost all Brazilian isolates were insensitive to metalaxyl.

Sensitivity of $P$. infestans isolates to mancozeb, chlorothalonil, and cymoxanil. For mancozeb, the $\mathrm{ED}_{50}$ for the majority of isolates (53 of 59) was $<1.0$ $\mu \mathrm{g} / \mathrm{ml}$ (Fig. 2A). For five isolates, $\mathrm{ED}_{50}$ values varied between 1 and $10 \mu \mathrm{g} / \mathrm{ml}$ and, for one isolate, $\mathrm{ED}_{50}$ was $25.7 \mu \mathrm{g} / \mathrm{ml}$. No isolate grew on medium which was amended with chlorothalonil at $>100$ $\mu \mathrm{g} / \mathrm{ml}$ (Fig. 2B). The $\mathrm{ED}_{50}$ for the majority of isolates (38 of 50) was $<1.0 \mu \mathrm{g} / \mathrm{ml}$. The numbers of isolates with $\mathrm{ED}_{50}$ values for chlorothalonil of between 1 and 10 $\mu \mathrm{g} / \mathrm{ml}$ and between 10 and $100 \mu \mathrm{g} / \mathrm{ml}$ were 10 and 2, respectively (Fig. 2B). For cymoxanil, the $\mathrm{ED}_{50}$ for all 47 isolates was $<1 \mu \mathrm{g} / \mathrm{ml}$ (Fig. 2C).

\section{DISCUSSION}

Isolates of $P$. infestans insensitive to metalaxyl were detected in all sampled areas from two Brazilian regions. Regardless of the region, there was no association between sensitivity and clonal lineage. In Brazil, populations of both lineages contained insensitive, intermediately insensitive, and sensitive isolates, similar to reports in The Philippines (23), South Africa (28), Uganda (31), some areas of Peru (32), and Ecuador (1), tropical or subtropical countries where clonal populations of $P$. infestans are found. In South Africa, sensitivity to metalaxyl among US-1 isolates varied according to the host; potato isolates were insensitive whereas tomato isolates were sensitive to metalaxyl (28). Host of origin was not associated with metalaxyl sensitivity among Brazilian US1 isolates.

The same mechanisms may have contributed to the evolution of metalaxyl insensitivity in US-1 and BR-1 populations. It seems that US-1 isolates originally were sensitive to metalaxyl (16). Mutation and subsequent selection could have resulted in variation in metalaxyl sensitivity in Brazilian isolates of $P$. infestans. Even though migration contributes to introducing insensitive isolates into an area (16), this does not seem to be the case for $P$. infestans in Brazil. The non-unimodal distributions of metalaxyl sensitivity for isolates of both lineages provides evidence against introduction of insensitive isolates from a founder population.

There were no quantitative differences in frequencies of metalaxyl sensitivity classes between US-1 and BR-1 isolates, but results varied according to the tests or criteria we used. For a given test, minor differences found in some regions or states could be due to local variation in metalaxyl usage or sampling artifact. More of a concern is the variation in ranking isolates that was found when different tests were used. Even though there are reports of correlation between agar and leaf disc methods $(15,27)$, we found no correlation between these methods using metalaxyl at either $5(r=0.17, P=0.369)$ or $100 \mu \mathrm{g} / \mathrm{ml}$ ( $r=-0.08, P=0.645)$. Considering that leaf-disc tests are more closely related to what happens in the field, this indicates that practical resistance to metalaxyl may occur in $P$. infestans populations in Brazil. Additional trials specifically planned to address the practical resistance issue are needed.

For the other fungicides we evaluated, $\mathrm{ED}_{50}$ values for most isolates were $<1$ $\mu \mathrm{g} / \mathrm{ml}$. Similar values of $E_{50}$ for mancozeb and cymoxanil have been reported for North American isolates of $P$. infestans $(22,45)$. For cymoxanil, no isolate had an $\mathrm{ED}_{50}>10 \mu \mathrm{g} / \mathrm{ml}$. A similar trend was reported for isolates of $P$. infestans from Mexico (45). Chlorothalonil inhibited $P$. infestans growth at low concentrations; the $\mathrm{ED}_{50}$ values for most isolates were $<10$ $\mu \mathrm{g} / \mathrm{ml}$. These findings suggest that there is no evidence of insensitivity in $P$. infestans populations to these compounds. Therefore, they can be used alone or in combination with systemic fungicides, such as metalaxyl.

Results from monitoring fungicide sensitivity studies are of great interest to plant pathologists, extension agents, and the industry sector. Knowledge of changes that occur in pathogen population in the field and the related causal factors may contribute to better understanding of epidemiology of late blight. Genetic shifts in pathogen populations can lead to reassessment of management strategies for controlling the disease. For late blight, this is of particular importance because (i) disease control is heavily based upon fungicide application, (ii) $P$. infestans is a high-risk pathogen for development of resistance to fungicide, and (iii) the high value of tomato or potato crops together with the destructiveness of late blight make yield losses a more serious issue. Monitoring activities should be continued to assess efficacy of fungicide resistance management.
ACKNOWLEDGMENTS

We thank Coordenação de Aperfeiçoamento de Pessoal de Nível Superior (CAPES) for providing a fellowship for A. Reis, and the Conselho Nacional de Desenvolvimento Científico e Tecnológico (CNPq) for providing fellowships for L. A. Maffia and E. S. G. Mizubuti.

\section{LITERATURE CITED}

1. Adler, N. E., Erselius, L. J., Chacon, M. G., Flier, W. G., Ordonez, M. E., Kroon, L. P. N. M., and Forbes, G. A. 2004. Genetic diversity of Phytophthora infestans sensu lato in Ecuador provides new insight into the origin of this important plant pathogen. Phytopathology 94:154-162.

2. Castro, C., and Shaw, D. S. 1992. Caracterização de isolados de Phytophthora infestans do Brasil. Fitopatol. Bras. 17:165.

3. Cohen, Y., and Coffey, M. D. 1986. Systemic fungicide and the control of oomycetes. Annu. Rev. Phytopathol. 24:311-338.

4. Davidse, L. C., Looijen, D., Turkensteen, L. J., and Van der Wal, D. 1981. Occurrence of metalaxyl-resistant strains of Phytophthora infestans in Dutch potato fields. Neth. J. Plant Pathol. 87:65-68.

5. Davidse, L. C., van den Berg-Velthuis, G. C. M., Mantel, B. C., and Jespers, A. B. K. 1991. Phenylamides and Phytophthora. Pages 349360 in: Phytophthora. J. A. Lucas, R. C. Shattock, D. S. Shaw, and L. R. Cooke, eds. Cambridge University Press, Cambridge.

6. Deahl, K. L., Pagani, M. C., Vilaro, F. L., Perez, F. M., Moravec, B., and Cooke, L. R. 2003. Characteristics of Phytophthora infestans isolates from Uruguay. Eur. J. Plant Pathol. 109:277-281.

7. Delp, C. J. 1980. Coping with resistance to plant disease control agents. Plant Dis. 64:652657.

8. Delp, C. J. 1988. Fungicide Resistance in North America. American Phytopathological Society Press, St. Paul, MN.

9. Dowley, L. J., and O'Sullivan, E. 1981. Metalaxyl-resistant strains of Phytophthora infestans (Mont.) de Bary in Ireland. Potato Res. 24:417-421.

10. Fabritius, A. L., Shattock, R. C., and Judelson, H. S. 1997. Genetic analysis of metalaxyl insensitivity loci in Phytophthora infestans using linked DNA markers. Phytopathology 87:1034-1040.

11. Forbes, G. A., Goodwin, S. B., Drenth, A., Oyarzun, P. J., Ordonez, M. E., and Fry, W. E. 1998. A global marker database for Phytophthora infestans. Plant Dis. 82:811-818.

12. Fry, W. E., and Goodwin, S. B. 1997. Resurgence of the Irish Potato Famine fungus. Bioscience 47:363-371.

13. Gisi, U., Chin, K. M., Knapova, G., Kung Farber, R., Mohr, U., Parisi, S., Sierotzki, H., and Steinfeld, U. 2000. Recent developments in elucidating modes of resistance to phenylamide, DMI and strobilurin fungicides. Crop Prot. 19:863-872.

14. Gisi, U., and Cohen, Y. 1996. Resistance to phenylamide fungicides: A case study with Phytophthora infestans involving mating type and race structure. Annu. Rev. Phytopathol. 34:549-572.

15. Goodwin, S. B., Smart, C. D., Sandrock, R. W., Deahl, K. L., Punja, Z. K., and Fry, W. E. 1998. Genetic change within populations of Phytophthora infestans in the United States and Canada during 1994 to 1996: Role of migration and recombination. Phytopathology 88:939-949.

16. Goodwin, S. B., Sujkowski, L. S., and Fry, W. E. 1996. Widespread distribution and probable origin of resistance to metalaxyl in clonal genotypes of Phytophthora infestans in the United States and Western Canada. Phytopathology 86:793-799. 
17. Grünwald, N. J., Flier, W. G., Sturbaum, A. K., Garay-Serrano, E., van den Bosch, T. B. M., Smart, C. D., Matuszak, J. M., LozoyaSaldaña, H., Turkensteen, L. J., and Fry, W. E. 2001. Population structure of Phytophthora infestans in the Toluca Valley region of Central Mexico. Phytopathology 91:882-890.

18. Hijmans, R. J., Forbes, G. A., and Walker, T. S. 2000. Estimating the global severity of potato late blight with GIS-linked disease forecast models. Plant Pathol. 49:697-705.

19. Hubert, J. J. 1992. Bioassay. Kendall/Hunt Publishing Company, Dubuque, IA.

20. Instituto Brasileiro de Geografia e Estatística 2004. Levantamento sistemática da produção agrícola. IBGE, Brasilia, Brazil.

21. Judelson, H. S., and Roberts, S. 1999. Multiple loci determining insensitivity to phenylamide fungicides in Phytophthora infestans. Phytopathology 89:754-760.

22. Kato, M., Mizubuti, E. S., Goodwin, S. B., and Fry, W. E. 1997. Sensitivity to protectant fungicides and pathogenic fitness of clonal lineages of Phytophthora infestans in the United States. Phytopathology 87:973-978.

23. Koh, Y. J., Goodwin, S. B., Dyer, A. T., Cohen, B. A., Ogoshi, A., Sato, N., and Fry, W. E. 1994. Migrations and displacements of Phytophthora infestans populations in East Asian countries. Phytopathology 84:922-927.

24. Köller, W. 1998. Chemical approaches to managing plant pathogens. Pages 337-376 in: Handbook of Pest Management. J. R. Ruberson, ed. Marcel Dekker, Inc., New York.

25. Köller, W., and Scheinpflug, H. 1987. Fungal resistance to sterol biosynthesis inhibitors: A new challenge. Plant Dis. 71:1066-1074.

26. Lee, T. Y., Mizubuti, E., and Fry, W. E. 1999. Genetics of metalaxyl resistance in Phytophthora infestans. Fungal Genet. Biol. 26:118-130.

27. Matuszak, J. M., Fernadez-Elquezabal, J., Gu, W. K., Villareal-Gonzalez, M., and Fry, W. E. 1994. Sensitivity of Phytophthora infestans populations to metalaxyl in Mexico: distribution and dynamics. Plant Dis. 78:911-916.

28. McLeod, A., Denman, S., Sadie, A., and Denner, F. D. N. 2001. Characterization of South African isolates of Phytophthora infestans. Plant Dis. 85:287-291.

29. Milgroom, M. G., Levin, S. A., and Fry, W. E. 1989. Population genetics theory and fungicide resistance. Pages 340-367 in: Plant Disease Epidemiology. K. J. Leonard, and W. E. Fry, eds. McGraw-Hill, New York.

30. Mizubuti, E. S. G. 2001. Requeima ou mela da batata e do tomate. Pages 100-174 in: Doenças causadas por Phytophthora no Brasil. E. D. N. Luz, A. F. Santos, K. Matsuoka, and J. L. Bezerra, eds. Livraria Editora Rural, Campinas, Brazil.

31. Ochwo, M. K. N., Kamoun, K., Adipala, E., Rubaihayo, P. R., Lamour, K., and Olanya, M. 2002. Genetic diversity of Phytophthora infestans (Mont.) de Bary in the Eastern and Western highlands of Uganda. J. Phytopathol. 150:541-542.

32. Perez, W. G., Gamboa, J. S., Falcon, Y. V., Coca, M., Raymundo, R. M., and Nelson, R. J. 2001. Genetic structure of Peruvian populations of Phytophthora infestans. Phytopathology 91:956-965.

33. Reis, A., Smart, C. D., Fry, W. E., Maffia, L. A., and Mizubuti, E. S. G. 2003. Characterization of Phytophthora infestans isolates from Southern and Southeastern Brazil from 1998 to 2000. Plant Dis. 87:896-900.

34. Ribeiro, F. H. S., Diniz, L. P., Reis, A., Halfeld Vieira, B. A., and Mizubuti, E. S. G. 2000. Avaliação de meios de cultura para crescimento e esporulação de Phytophthora infestans. Fitopatol. Bras. 25 (Suppl.):415.

35. Riveros, F. B., Sotomayor, R., Rivera, R., Secor, G., and Espinoza, B. 2003. Resistencia de Phytophthora infestans (Montagne) de Bary a metalaxil en cultivo de papas en el Norte de Chile. Agric. Tec. 63:117-124.

36. Rodríguez, D. 2001. Compatibilidad sexual, reaccion a metalaxyl y agresividad de aislamientos venezolanos de Phytophthora infestans. Fitopatol. Venez. 14:13-18.

37. Shattock, R. C. 2002. Phytophthora infestans: populations, pathogenicity and phenylamides. Pest Manage. Sci. 58:944-950.

38. Snedecor, G. W., and Cochran, W. G. 1989. Statistical Methods. Iowa State University Press, Ames.

39. Sozzi, D., Schwinn, F. J., and Gisi, U. 1992 Determination of the sensitivity of Phytophthora infestans to phenylamides: a leaf disc method. Bull. OEPP 22:306-309.

40. Sozzi, D., and Staub, T. 1987. Accuracy of methods to monitor sensitivity of Phytophthora infestans to phenylamide fungicides. Plant Dis. 71:422-425.

41. Spielman, L. J., McMaster, B. J., and Fry, W. E. 1989. Dominance and recessiveness at loc for virulence against potato and tomato in $P h y-$ tophthora infestans. Theor. Appl. Genet. $77: 832-838$

42. Staub, T. 1991. Fungicide resistance: practical experience with antiresistance strategies and the role of integrated use. Annu. Rev. Phytopathol. 29:421-442.

43. Steffens, J. J., Pell, E. J., and Tien, M. 1996 Mechanisms of fungicide resistance in phytopathogenic fungi. Curr. Opin. Biotechnol. 7:348-355.

44. Suassuna, N. D., Maffia, L. A., and Mizubuti, E. S. G. 2004. Aggressiveness and host specificity of Brazilian isolates of Phytophthora in festans. Plant Pathol. 53:405-413.

45. Sujkowski, L. S., Fry, B. A., Power, R. J., Goodwin, S. B., Peever, T. L., Hamlen, R. A., and Fry, W. E. 1995. Sensitivities of Mexican isolates of Phytophthora infestans to chlorothalonil, cymoxanil, and metalaxyl. Plant Dis. 79:1117-1120.

46. Williams, R. J., and Gisi, U. 1992. Monitoring pathogen sensitivity to phenylamide fungicides: Principles and interpretation. Bull OEPP 22:299-306. 